\title{
Assessment of water quality in an artificial urban canal: A case study of Songdo City in South Korea
}

\author{
Jungkyu Ahn, Yeji Na, Sung Won Park \\ Department of Civil and Environmental Engineering, Incheon National University, Incheon 22012, Republic of Korea
}

\begin{abstract}
Currently, the waterfront facility was constructed in New Songdo City, South Korea. It has the various water leisure areas and especially an artificial urban canal with filtered seawater by re-circulating flow system. However, due to excessive amount of nutrients from seawater combined with complicated geometry, it is highly vulnerable to deterioration of water quality. In this study, flow characteristics and pollutant transport were analyzed with comprehensive numerical models, MIKE 3 FM and ECO-lab. Based on these numerical results, notable sampling points were selected for field measurements and comparison between modeling and measured results were conducted. In addition, the integrated water quality evaluation index, Water Quality Index was applied to analyze various water quality issues. We also set up scenarios to control the two kinds of water quality factors, dissolved oxygen (DO), and total phosphorus (TP). As a result, the effect of $20 \%$ reduction of TP was less than $10 \%$ and it was almost ineffective for a year but it was reduced by up to $40 \%$ in case of scenario which DO is increased by $20 \%$. Therefore, it was recommended to control the DO concentration, usually by applying re-aeration facility, rather than TP in artificial urban canal with seawater.
\end{abstract}

Keywords: Artificial urban canal, Dissolved oxygen, ECO-lab, MIKE 3 FM, Total phosphorus, Water quality index

\section{Introduction}

An artificial urban canal was built and operated with water supply and re-circulation system from the sea in New Songdo City, which is developing a waterfront area for an eco-friendly green city. Inlet water is filtered and supplied with seawater from the West sea of South Korea. The main goal of the canal construction is to provide amenities along the waterfront area with safe water environment. Due to the geometric characteristics such as, channel junction and abrupt changes of cross section, flow patterns are complicated and the water flow is rather slow overall. Such a flow pattern makes a relatively long time to transfer the pollutants all the way to the outlet when they are introduced into the canal. Therefore, flowing water in the canal can be threatened by eutrophication and algae bloom with excessive nutrients of seawater from the West coast in South Korea. In addition, seasonal variation of temperature leads various water quality problems. Therefore, it is necessary to understand the flow characteristics and pollutant behavior, and it is possible to operate and manage the canal efficiently. In this study, flow characteristics of the canal were analyzed using hydrodynamic numerical model for flow characteristics, MIKE $3 \mathrm{FM}$, and transport of conservative pollutant were analyzed by using water quality module, ECO-lab. Considering the numerical results, we selected the five sampling points including the regularly monitoring point by KMEMC (Korea Marine Environment Management Corporation) in the canal and measured the water quality items with the field apparatus [1]. In addition, we tried to evaluate the water quality grades which include all the characteristics of fundamental water quality issues, using the time series data. Then, we simulated and compared the reasonable scenarios for the appropriate management in the future and proposed one as an effective water quality maintenance method along the canal. There have been several previous researches on the water quality evaluation and numerical simulations on the ecological topics near the west coast. From 1995 to 1996, Yeo and Kang [2] analyzed the water quality and phytoplankton communities in the coastal area of Incheon and various water quality factors were estimated. In particular, the seasonal pattern was analyzed based on the annual survey data, but there is a limitation in evaluating overall water quality because the grades
This is an Open Access article distributed under the terms of the Creative Commons Attribution Non-Commercial License (http://creativecommons.org/licenses/by-nc/3.0/) which permits unrestricted non-commercial use, distribution, and reproduction in any medium, provided the original work is properly cited.

Copyright (C) 2019 Korean Society of Environmental Engineers
Received August 12, 2018 Accepted November 23, 2018

${ }^{\dagger}$ Corresponding author

Email: billy1006@gmail.com

Tel: +82-32-835-8084

ORCID: 0000-0002-7175-9765 
for each individual water quality item were calculated instead of the integrated water quality grade [2]. Carpenter et al. [3] investigated the relationship between total nitrogen (TN) and various aquatic bacteria along the coast line in USA. They also insisted the algal blooms can occur naturally under certain water and weather conditions [3]. Jones et al. [4] analyzed the results of an intensive sampling effort by the Integration and Application Network in the Maryland Coastal Bays (IANMCB) [4]. A spatially explicit water quality index (WQI) index was developed from standard water quality analyses and a new stable isotope technique. However, this research has no analysis of temporal changes of water quality distribution. Recently, accuracy and processing speed of the commercial numerical simulation models has rapidly been improved and this research also applied a commercial numerical model, MIKE software package, which is well-known for the flow and pollutant transport simulation models in rivers and oceans. And we intended to comprehend the current status of the canal and suggest effective alternatives for the canal operation and maintenance.

\section{Description of Application Site}

An artificial urban canal using seawater supply system from Incheon coast (West coast of South Korea) was constructed and has been operating in the Central Park, New Songdo city, South Korea in 2009 (Fig. 1). The area of the Central Park in New Songdo city is $411,324 \mathrm{~m}^{2}$ and the park was constructed to provide the aquatic recreation and leisure for residents. The canal in the park has a partially closed water circulation system, the canal, and its dimensions are $1.8 \mathrm{~km}$ long, $1.5 \mathrm{~m}$ deep and $110 \mathrm{~m}$ wide. Filtered and treated seawater by Seawater Treatment Facility (STF) from the west coast is supplied through two inlets to the canal. Here, discharges are 116 and 15 liters per second at two inlets \#1 (Anapji) and \#2 (Boat House), respectively. The canal is 1.5 $\mathrm{m}$ deep and flow velocity is maintained by the weir at the outlet. Seawater is supplied to the canal through a $5 \mu \mathrm{m}$ pore size filter system from two inlets and discharged to the sea. It was reported that various species of phytoplankton communities inhabit near the sea [2]. Due to the seawater, active growth of phytoplankton communities can cause the growth of algal blooms when excess nutrients, e.g. eutrophication, can be introduced into the canal. There are two major considerations for maintenance and operation: 1) water quality from the STF 2) and relatively very low velocity profile through the canal. Due to the seawater from the STF, phytoplankton communities can cause the growth of algal blooms with the excessive nutrients in the canal. Therefore, a proper nutrient balance in the canal is very important for prohibiting and controlling algal blooms, especially for the scum, bad smell, and red tides. Filtration and less than $10 \mathrm{~d}$ of hydraulic retention duration may prevent algal blooms and the deterioration of the water quality [5]. In addition, typical horizontal flow distribution near the confluence can also influence the pollutant behavior. Especially, it is evident that nutrient-related eutrophication is one of the most remarkable problems with respect to the water quality of two inlets. For the sustainable maintenance of the canal, proper understandings of the current situation of the canal are necessary, and alternatives for appropriate management of the canal should be suggested.

\section{Methodologies}

Because the purpose of this study was to understand the flow characteristics and pollutant transport in the canal for sustainable management and operation, we setup the numerical mesh geometry and simulated three-dimensional flow analysis and pollutant behavior model with condition of current state, i.e. inlet discharge, outlet water depth, an hourly-monitored data of dominant water quality issues including dissolved oxygen (DO), chemical oxygen

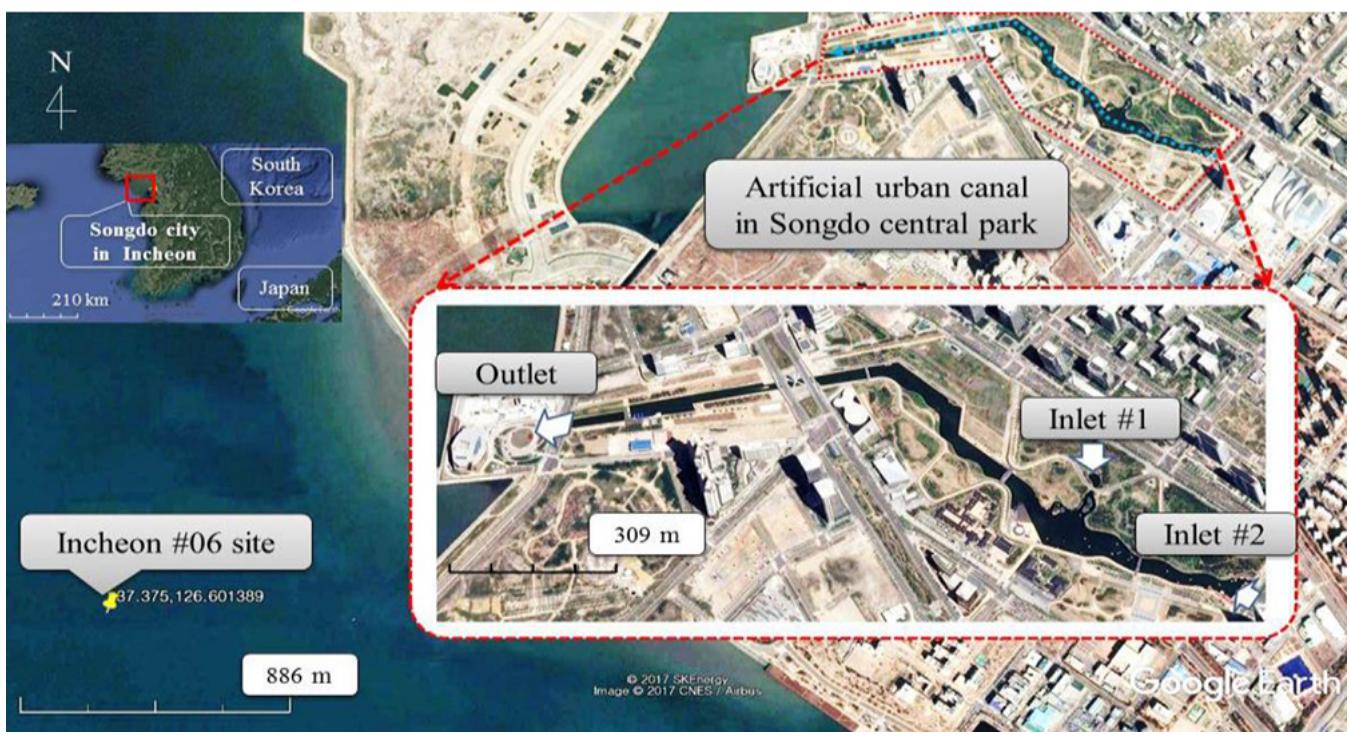

Fig. 1. Location of Songdo Waterfront area and monitoring site (modified from Google Earth). 
demand (COD), TN, total phosphorus (TP). We used the hydrodynamic and ECO-lab module of MIKE 3 FM to simulate depth averaged two-dimensional flow and conservative pollutant transport, respectively. Based on the simulation results, the sampling points which should be considered were selected. The measured data in at each sampling point were compared with the hourly monitoring data in the West coast. In addition, for proper operation of the canal, a representative water quality assessment method was used to evaluate the water quality status by National Fisheries Research and Development Institute (NFRDI) from 2010 to 2014. Also this WQI score and grade were estimated with the additional data of water quality, Chlorophyll-a (Chl-a), Secchi disk depth (turbidity).

\section{Numerical Modeling}

Most of 3-D hydrodynamic numerical models utilize the Navier-Stokes equations. These models can either be setup with structured (rectangular) or unstructured (triangular and rectangular) mesh grid types, with both approaches being widely adopted widely for a range of hydraulic applications. The structured grids can be rectilinear or curvilinear and typically adopt a Finite Difference Method (FDM) scheme, while the unstructured grids have a flexible mesh (mesh elements can have a variable shape and size over the model domain) and typically adopt a finite volume solution scheme [6]. Toombes and Chanson [7] applied the four different numerical models on the experimental results of the weir test and compared each other. In Table 1, specifications of the most widely adopted hydrodynamic models, Flow-3D and MIKE 3 FM were compared in detailed [8].

And MIKE model has the most effective type of mesh grid, unstructured and flexible, and also has the coupling calculation option with ECO-lab.

\subsection{Governing Equations}

MIKE 3 FM is a comprehensive three dimensional water modeling system developed by DHI Company. The modeling system of MIKE 3 FM is based on the numerical solution of two/three-dimensional incompressible RANS model (Reynolds averaged the Navier-Stokes equation model) with Boussinesq and hydrostatic pressure assumptions. Thus, the model consists of continuity, momentum, temperature, salinity, and density equations and it is closed by a turbulent closure scheme. The density does not depend on the pressure, but only the temperature and the salinity. For the three-dimensional model, the free surface is considered by using a sigma-coordinate transformation approach or a combination of a sigma and $z$-level coordinate system. The governing equation of continuity is:

$$
\frac{\partial u}{\partial x}+\frac{\partial v}{\partial y}+\frac{\partial w}{\partial z}=S
$$

where $x, y$, and $z$ are the Cartesian coordinates (m) and $u, v$, and $w$ are the three dimensional flow velocity components $\left(\mathrm{ms}^{-1}\right)$ in the $x, y$, and $z$ direction, respectively. $S\left(\mathrm{~s}^{-1}\right)$ is the magnitude of the discharge due to point source term. And two horizontal

Table 1. Comparisons of Hydrodynamic Numerical Models

\begin{tabular}{|c|c|c|}
\hline Description \Model & FLOW-3D & MIKE 3 FM \\
\hline Hydrodynamic equation & $\begin{array}{l}\text { 3-D Reynolds Averaged } \\
\text { Navier Stokes Equation }\end{array}$ & $\begin{array}{l}\text { 3-D Reynolds Averaged } \\
\text { Navier Stokes Equation }\end{array}$ \\
\hline Application area (examples) & $\begin{array}{l}\text { Free surface modeling, } \\
\text { Fluid flow in complex geometry as dams / bridges, } \\
\text { Metal casting, inkjet modeling } \\
\text { Coastal and marine areas }\end{array}$ & $\begin{array}{l}\text { Structures and plants in stratified waters, } \\
\text { Coastal and oceanographic circulation, } \\
\text { Lake hydrodynamics and ecology, } \\
\text { Coastal, thermal, wastewater disposal outlets }\end{array}$ \\
\hline Mesh formation & $\begin{array}{l}\text { Structured / Unstructured } \\
\text { Fixed mesh }\end{array}$ & $\begin{array}{l}\text { Structured / Unstructured } \\
\text { Fixed mesh / Flexible mesh* }\end{array}$ \\
\hline Discretization & Finite Difference Method / Control volume mesh & Finite Difference Method \\
\hline Turbulence models & $\begin{array}{l}\text { RNG model, } \\
\text { Two eq. } k-\varepsilon \text { model, } \\
\text { Two eq. } k-\omega \text { model, } \\
\text { Large eddy simulation }\end{array}$ & $\begin{array}{l}\text { Constant eddy viscosity model, } \\
\text { Smagorinsky eddy viscosity model, } \\
k \text { model, Two eq. } k-\varepsilon \text { model, } \\
\text { Mixed Smagorinsky (horizontal) } \\
+k-\varepsilon \text { model (vertical) }\end{array}$ \\
\hline Multiphase treatment & Volume of Fluid (VOF) & $\begin{array}{l}\text { Various modules such as sediment transport, } \\
\text { particle tracking, etc. }\end{array}$ \\
\hline Vertical momentum & Non-hydrostatic modeling & $\begin{array}{l}\text { Hydrostatic assumption / Non-hydrostatic } \\
\text { (Artificial compressibility method) }\end{array}$ \\
\hline Cost & $\begin{array}{l}\text { Academic Research } \\
\text { Annually } \$ 5,000\end{array}$ & $\begin{array}{l}\text { Academic Research } \\
\text { (1 mon free })\end{array}$ \\
\hline Parallel processing & \multicolumn{2}{|c|}{ Optimized for multicore } \\
\hline
\end{tabular}


momentum equations, Eq. (2) and (3), for the $x$ - and $y$ - component, are as follows, respectively:

$$
\begin{aligned}
& \frac{\partial u}{\partial t}+\frac{\partial u^{2}}{\partial x}+\frac{\partial u v}{\partial y}+\frac{\partial u w}{\partial z}=f v-g \frac{\partial \eta}{\partial x}-\frac{1}{\rho_{0}} \frac{\partial p_{a}}{\partial x} \\
& -\frac{g}{\rho_{0}} \int_{z}^{\eta} \frac{\partial \rho}{\partial x} d z-\frac{1}{\rho_{0} h}\left(\frac{\partial S_{x x}}{\partial x}+\frac{\partial S_{x y}}{\partial y}\right)+F_{u}+\frac{\partial}{\partial z}\left(v_{t} \frac{\partial u}{\partial z}\right)+u_{s} S \\
& \frac{\partial v}{\partial t}+\frac{\partial v^{2}}{\partial y}+\frac{\partial u v}{\partial x}+\frac{\partial v w}{\partial z}=-f u-g \frac{\partial \eta}{\partial y}-\frac{1}{\rho_{0}} \frac{\partial p_{a}}{\partial y} \\
& -\frac{g}{\rho_{0}} \int_{z}^{\eta} \frac{\partial \rho}{\partial y} d z-\frac{1}{\rho_{0} h}\left(\frac{\partial S_{y x}}{\partial x}+\frac{\partial S_{y y}}{\partial y}\right)+F_{v}+\frac{\partial}{\partial z}\left(v_{t} \frac{\partial v}{\partial z}\right)+v_{s} S
\end{aligned}
$$

where $t$ (s) is the time; $\eta(\mathrm{m})$ is bed elevation; and $f\left(\mathrm{~s}^{-1},=2 \Omega \sin \theta\right.$, $\Omega$ and $\theta$ are the angular rate of revolution and the geographic latitude, respectively, is the Coriolis parameter, which was not considered in this research. $g\left(\mathrm{~ms}^{-2}\right)$ represents the gravitational acceleration; $\rho$ and $\rho_{0}\left(\mathrm{tm}^{-3}\right)$ are the density of water and the reference density of water; $S_{x x}, S_{x y}, S_{y x}$ and $S_{y y}\left(\mathrm{ts}^{-2}\right)$ are components of the radiation stress tensor; $v_{t}\left(\mathrm{~m}^{2} \mathrm{~s}^{-1}\right)$ is the vertical turbulent viscosity, derived from the log-law and expressed as $\left(v_{t}=c_{\mu} k^{2} / \varepsilon\right)$; $c_{\mu}(-)$ is an empirical constant; $k\left(\mathrm{~m}^{2} \mathrm{~s}^{-2}\right)$ is the turbulent kinetic energy; $\varepsilon\left(\mathrm{m}^{2} \mathrm{~s}^{-3}\right)$ is the turbulence dissipation. $P_{a}\left(\mathrm{tm}^{-1} \mathrm{~s}^{-2}\right)$ is the atmospheric pressure. $u_{s}$ and $v_{s}$ are velocity by which the water is discharged into the ambient water. $F_{u}$ and $F_{V}\left(\mathrm{~ms}^{-2}\right)$ are the horizontal stress terms and they are described using a gradient-stress relation, which is simplified to:

$$
\begin{aligned}
& F_{u}=\frac{\partial}{\partial x}\left(2 A \frac{\partial u}{\partial x}\right)+\frac{\partial}{\partial y}\left(A\left(\frac{\partial u}{\partial y}+\frac{\partial v}{\partial x}\right)\right) \\
& F_{v}=\frac{\partial}{\partial y}\left(2 A \frac{\partial v}{\partial y}\right)+\frac{\partial}{\partial x}\left(A\left(\frac{\partial u}{\partial y}+\frac{\partial v}{\partial x}\right)\right)
\end{aligned}
$$

where $A\left(\mathrm{~m}^{2} \mathrm{~s}^{-1}\right)$ is the horizontal eddy viscosity [9].

\subsection{Water Quality Modeling}

To analyze the water quality simulation in the canal, MIKE ECO-lab coupled with the MIKE 3 FM flow model, was applied with hourly input data of water quality. During simulation the model system integrates one time step by simulating the transport of advection variables based on hydrodynamics. All properties of concentration such as, initial concentrations, continuously updated advection and dispersion coefficients, and updated forcing functions, are loaded into the ECO-lab module and then the module evaluates all the calculations which integrate one time step, and returns updated concentration results to the flow model system that advances each time step. Thus, water quality issues were simulated using MIKE 3 FM ECO-lab module, which is a numerical model for three-dimensional ecological modeling [10].

\subsection{WQI Estimation}

To evaluate the water quality of river and ocean, and to provide the reasonable condition in water environment, comprehensive and integrated index of water quality issues has been demanded. Newly developed evaluation index about integrated water quality issues, WQI by KMEMC was applied in this research. WQI is determined by values of saturated DO (\%), Chl-a ( $\mu \mathrm{g} / \mathrm{L})$, Secchi Disk depth (m), dissolved inorganic phosphorus (DIP, $\mu \mathrm{g} / \mathrm{L}$ ), and dissolved inorganic nitrogen (DIN, $\mu \mathrm{g} / \mathrm{L}$ ) as follows:

$$
\begin{gathered}
\text { WQI }=10 \times(\text { Saturated DO })+ \\
6\left[\frac{(\text { Chl-a })+(\text { Secchidisk })}{2}\right]+4 \times\left(\frac{\mathrm{DIN}+\mathrm{DIP}}{2}\right)
\end{gathered}
$$

And this score of the WQI was classified with the five grades in Table 2.

\section{Numerical Simulation and Field Measurement}

\subsection{Model Setup}

For the model geometry of the canal, mesh-generator of MIKE 3 FM was used. Dimensions of the canal are about 1,800 m long and up to $110 \mathrm{~m}$ wide. Improving calculation efficiency of the simulation, the canal boundary was built with 949 nodes and 634 elements. Effective triangular (unstructured) grids were created to precisely implement the complex topography [6]. In Fig. 2, the effective mesh grid networks and boundary conditions are

\begin{tabular}{|c|c|c|c|c|c|c|c|c|}
\hline \multicolumn{2}{|c|}{ WQI properties } & \multicolumn{7}{|c|}{ WQI parameter } \\
\hline Grade & Score & Point & Chl-a $(\mu \mathrm{g} / \mathrm{L})$ & Sat. DO (\%) & DIN $(\mu \mathrm{g} / \mathrm{L})$ & $\mathrm{DIP}(\mu \mathrm{g} / \mathrm{L})$ & Secchi Disk (m) & Remarks \\
\hline I & $0-23$ & 1 & 2.20 & 90.0 & 425.00 & 30.0 & 1.00 & \multirow{4}{*}{ less than } \\
\hline II & $24-33$ & 2 & 2.42 & 81.0 & 467.50 & 33.0 & 0.90 & \\
\hline III & $34-46$ & 3 & 2.75 & 67.5 & 531.25 & 37.5 & 0.75 & \\
\hline IV & $47-59$ & 4 & 3.30 & 45.0 & 637.50 & 45.0 & 0.50 & \\
\hline $\mathrm{V}$ & $60-$ & 5 & 3.30 & 45.0 & 637.50 & 45.0 & 0.50 & larger than \\
\hline
\end{tabular}
illustrated. The upstream boundaries of two inlets to the canal were setup with discharges of 116 and 15 liters per second and the downstream condition was kept with water depth of $1.5 \mathrm{~m}$. Lee et al. [5] analyzed the effect of the three-dimensional flow pattern on the algal blooms in the canal of New Songdo City, South Korea. They conducted the field measurement and numerical

Table 2. Classification of WQI (KMEMC) Properties 


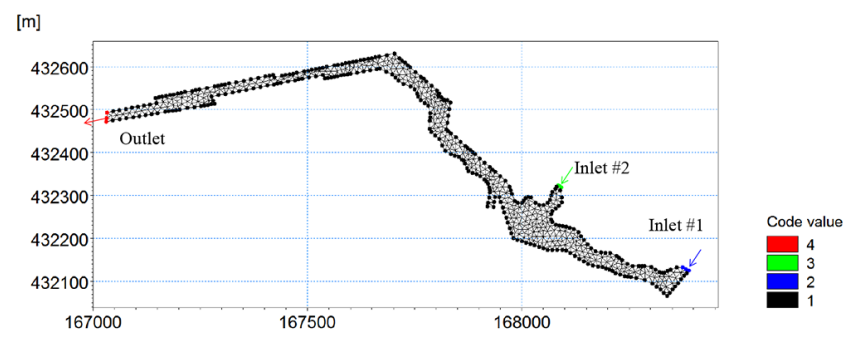

Fig. 2. Mesh geometry and boundaries of application site (code : outer boundary; code 2: inlet \#1; code 3: inlet \#2; code 4: outlet).

simulations of flow velocity near the confluence. And especially, they insisted that an intensity of vorticity in the water-depth direction is the most dominant parameter on the actions of algal blooms. In this study, we considered the vertical distribution of flow and pollutant transport with 5 layers in vertical direction.

\subsection{Flow Characteristics}

Simulated results of depth averaged two-dimensional flow distribution are shown in Fig. 3. Flow characteristics were partially analyzed due to the various geographical features and plotted in Fig. 4. We chose four areas to analyze flow characteristics in detail.

[m]

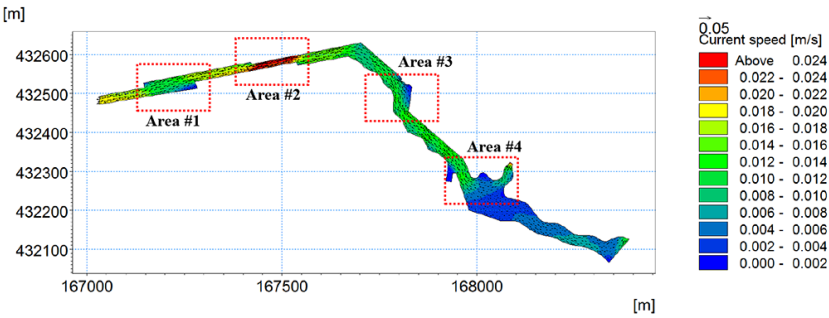

Fig. 3. Two-dimensional flow distribution of numerical simulation in whole domain.
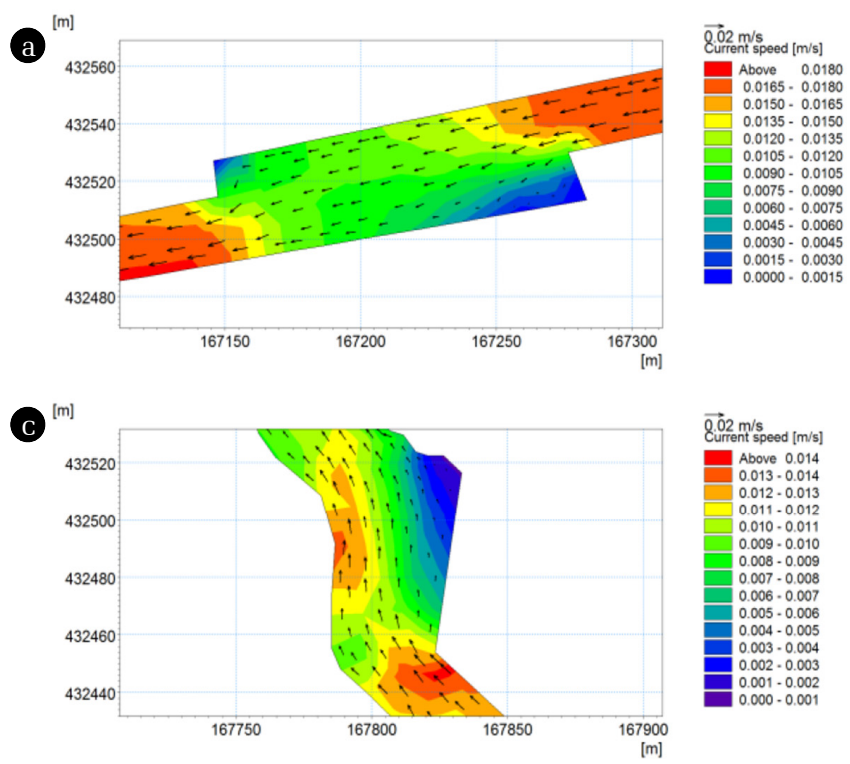

Especially due to a typical confluence at the junction of the inlet \#2 and the curved main channel from the inlet \#1, flow feature in area \#4 is not typical with flow deflection, stagnation, separation, and recirculation [11]. In area \#4, where the cross section was abruptly decreased, the flow velocity increased and stagnation of flow occurred in the left side as shown as circled part in Fig. 4. Also in the right bank of area \#3, there was a flow dead zone. In the area \#2, where the section was suddenly shrunk to the left, the fastest flow rate occurs. Near the end of the canal, the flow velocity decreases relatively rapidly in the area \#1, which was enlarged at the upstream of the canal end. At the left bank of entrance and the right bank of the canal end in the area \#1, there were also local flow dead zone, which means the flow velocity is relatively very slow. Along the canal, the water quality deterioration due to the flow congestion was expected due to the local flow dead zone in the left and right sides of the canal, and also it was expected to be the most vulnerable to deterioration of algal bloom due to the confluence of two inlets and abrupt increase of channel width at the canal end.

\subsection{Pollutant Transport Distribution}

In order to select sampling points in the field, pollutant transport in the canal was simulated in the condition of continuous inflow of $1 \mathrm{mg} / \mathrm{L}$ of conservative pollutant into each of the two inlet boundaries. Pollutant concentration distributions changes with time were plotted in Fig. 5. As a result, after $10 \mathrm{~h}$, the transverse dispersion of pollutant was completed. Also, after about $21 \mathrm{~h}$, it was confirmed that the pollutant cloud introduced from the two inlets overlapped. At $31 \mathrm{~h}$, pollutant clouds were merged in the confluence and pollutants discharge at the downstream was expected. After $60 \mathrm{~h}, 2.5 \mathrm{~d}$, it was analyzed that the pollutants were spread over the entire canal. From the results distribution of pollutant, area near the canal confluence was needed to be considered with field measurement.

\section{b ${ }_{432}^{[m]}$}
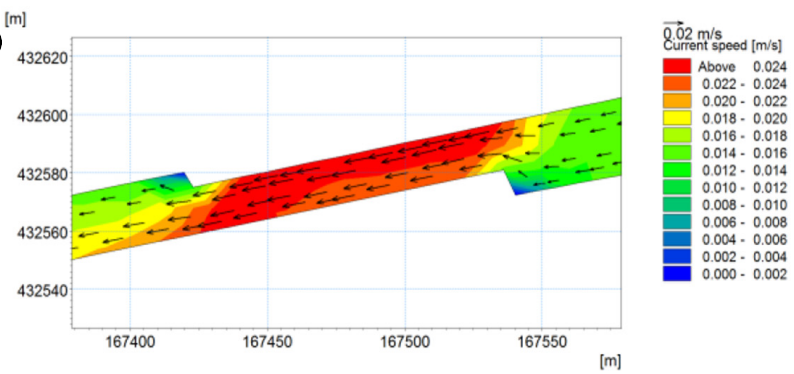

(a)

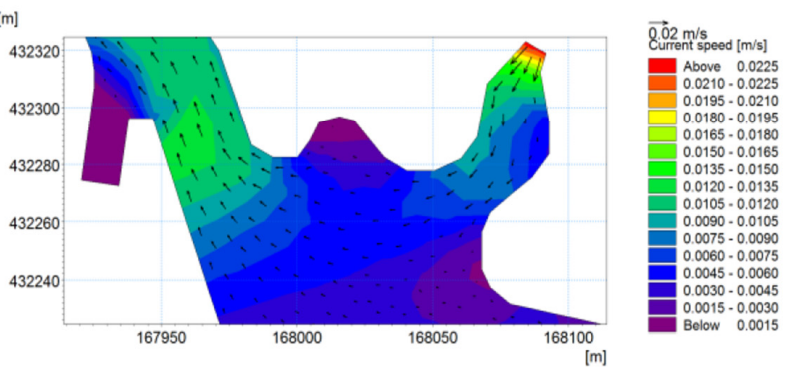

Fig. 4. Two-dimensional flow distribution of numerical simulation in local areas. (a) Area \#1, (b) Area \#2, (c) Area \#3, (d) Area \#4. 
[m]

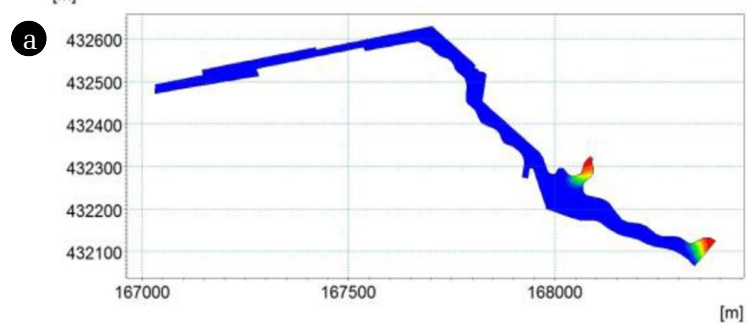

[m]
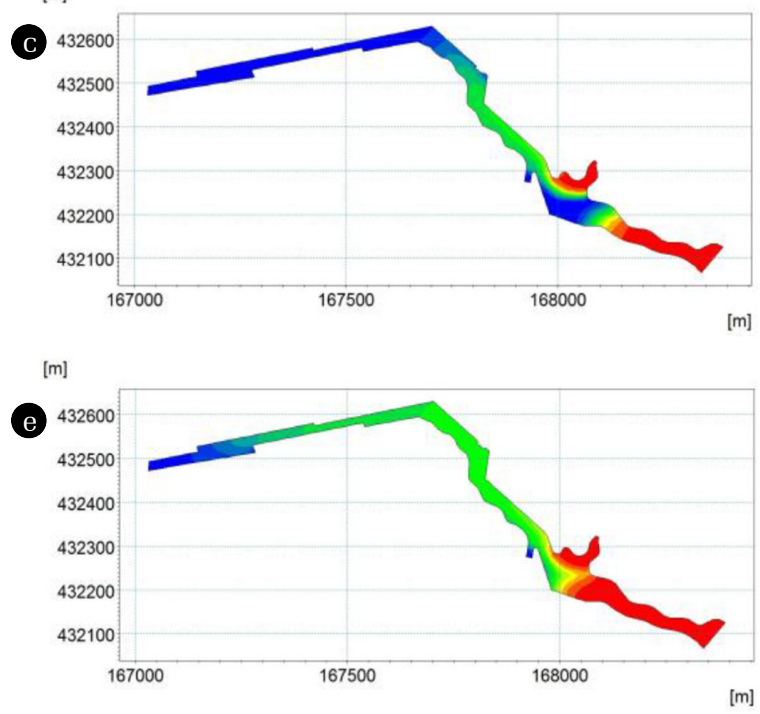

[m]

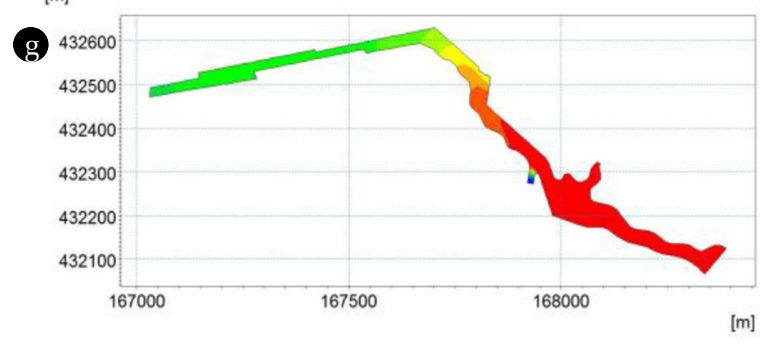

[m]

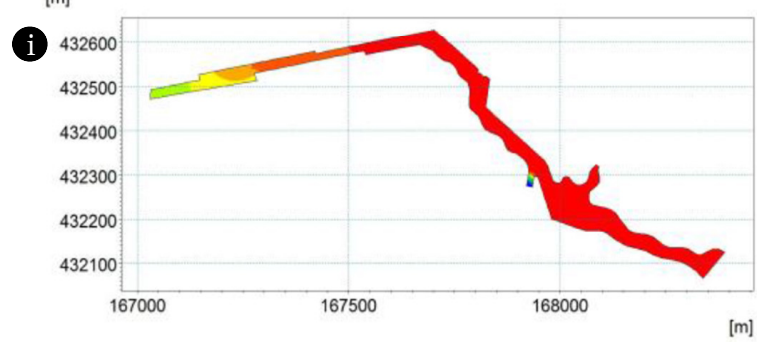

[m]
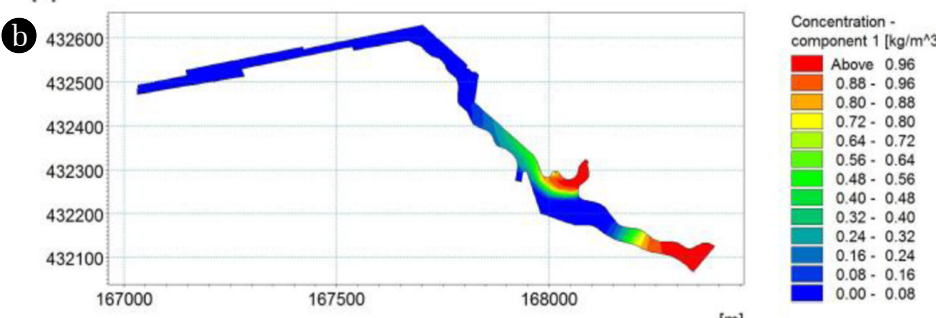

[m]

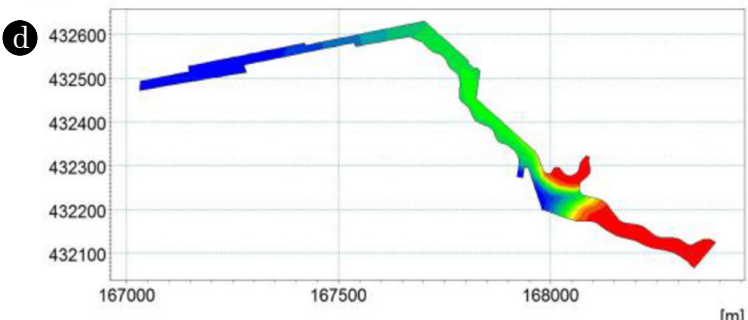

Concentration -

component $1 \mathrm{~kg} / \mathrm{m}$

$0.88 \cdot 0.96$

$0.80 \cdot 0.88$

$0.72 \cdot 0.80$

$0.64-0.72$

$0.56-0.64$

$0.48-0.56$

$0.40 \cdot 0.48$

$0.24-0.32$

$16-0.24$

$0.08-0.1$

[m]

[m]

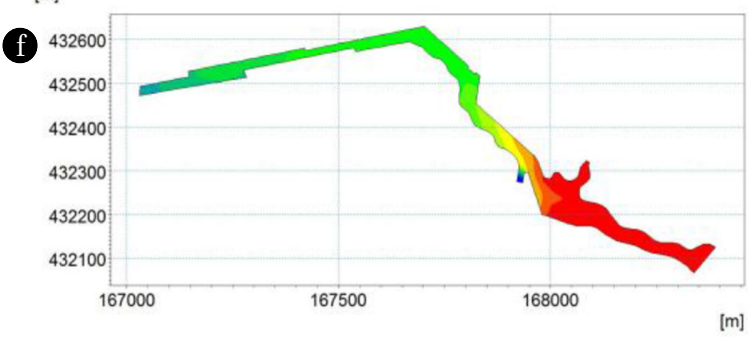

Concentration -
component $1\left[\mathrm{~kg} / \mathrm{m}^{\wedge}\right]$

component $1[\mathrm{~kg} / \mathrm{m}$

Above 0.96
$0.88-0.96$

$0.80 \cdot 0.88$

$0.72 \cdot 0.80$

$0.72 \cdot 0.80$

$0.56-0.64$

$0.48-0.56$

$0.40 \cdot 0.48$

$0.32 \cdot 0.40$

$0.24-0.32$

$0.16-0.24$

$0.08-0.16$

[m]

[m]

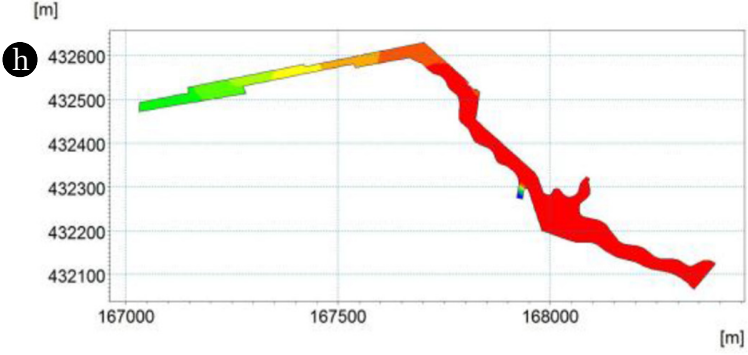

Concentration -
component $1\left[\mathrm{~kg} / \mathrm{m}^{1}\right)$

component $1[\mathrm{~kg} / \mathrm{m}$

Above 0.96
$0.88-0.96$

$0.80-0.88$

$0.72 \cdot 0.80$

$0.64 \cdot 0.72$

$0.56-0.64$

$0.48 \cdot 0.56$

$0.40 \cdot 0.48$

$0.32=0.40$
$0.24-0.32$

$0.24-0.32$

(1)

$0.08 \cdot 0.16$

[m]

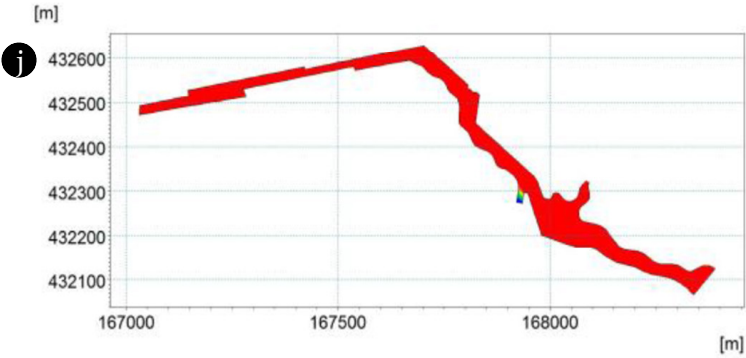

Concentration -
component $1\left[\mathrm{~kg} / \mathrm{m}^{\wedge} 3\right]$

Above 0.96

$0.88-0.96$

$0.80 \cdot 0.88$

$0.64-0.72$

$0.56-0.64$

$0.48 \cdot 0.56$

$0.40-0.48$

$0.32-0.40$

$0.16 \cdot 0.24$

$0.08 \cdot 0.16$

Fig. 5. Temporal changes of pollutant transport with continuous injection condition. (a) $2 \mathrm{~h}$ later, (b) $10 \mathrm{~h}$ later, (c) $16 \mathrm{~h}$ later, (d) $21 \mathrm{~h}$ later, (e) $26 \mathrm{~h}$ later, (f) $31 \mathrm{~h}$ later, (g) $38 \mathrm{~h}$ later, (h) $45 \mathrm{~h}$ later, (i) $50 \mathrm{~h}$ later, (j) $60 \mathrm{~h}$ later.

\subsection{Field Measurement}

Based on the numerical simulation results of the flow and pollutant transport, it was confirmed that the merging of pollutants from both inlets occurs near the inlet \#1, so in-situ observation was conducted near the confluence, point \#3. In addition, three other sampling points and one monitoring point (seawater) were de- 


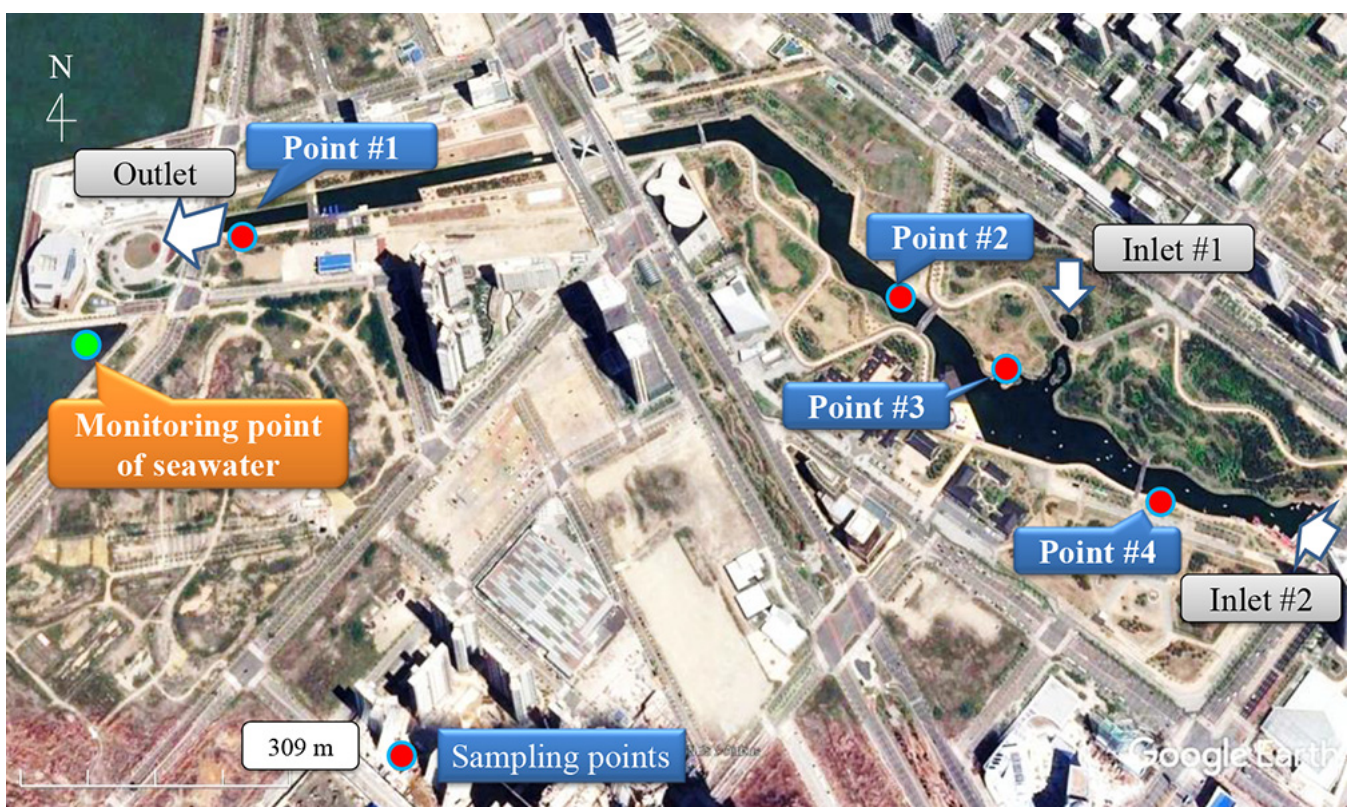

Fig. 6. Locations of sampling points in artificial canal in Songdo Waterfront area (modified image from Google Earth).

termined as shown in Fig. 6. A portable digital oxygen meter (model: DO-5510, Lutron Electronic Enterprise Co., Ltd) with polarographic type sensor was applied to field measurements of DO concentration (range: 0-20.0 mg/L; accuracy: $\pm 0.4 \mathrm{mg} / \mathrm{L}$ ) and water temperature (range: $0-50.0^{\circ} \mathrm{C}$; accuracy: $\pm 0.8^{\circ} \mathrm{C}$ ) [12]. Field measurement was performed three times from September to November. We also analyzed the concentration of TN and TP provided by KMEMC. Monthly measured and monitored data were compared. Fig. S1 represented that the water temperature results are not nearly the same as the seawater observations, and the standard deviation for 3 mon was estimated to be about $2 \%$. In addition, a difference of temperature between in September and October was the biggest due to abrupt declined concentration in seawater.

Also, DO results showed the highest in September when the water temperature was highest, and those in October and November decreased gradually as the water temperature decreased. The measured concentration values of TN at all sampling points in the canal were much smaller than the seawater concentration values. Especially in September and November, the difference almost exceeded two times of them. In other words, these results indicate that the nutrients increase sharply in coastal area. Finally, the TP concentration results in September were measured over about $0.07 \mathrm{mg} / \mathrm{L}$, but it decreased rapidly along the canal. However, as with the results of TP observations, it was analyzed that the concentration in the coast rapidly increased to about four times one in the canal.

\section{WQI Analysis}

\subsection{Determination of Simulation Period}

Recently, Jang and Park [13] analyzed the WQI analysis on the same canal as this study. They simulated the flow distribution and water quality issues in the canal with numerical models. They evaluated the WQI for a year with consideration of six parameters also. They only focused on the current state of the canal and did not consider any prediction analysis at all [13]. In this study, we provided the WQI scores in past $5 \mathrm{y}$ (from 2010 to 2014). Fig. S3 shows the variation of WQI values for every February, May, August, and November. The WQI scores did not exceed about 46 (grade of "poor”) only except May 2013. The WQI score in May 2013 was reported as the biggest as 52 and that means water quality is 'very poor'. Therefore, we chose 2013 as the target period for the WQI evaluation.

\subsection{WQI Estimation}

With the water quality data in 2013, we simulated the ECO-lab module with the same geometry. In Fig. S2, seasonal variation of six water quality factors, COD, TN, TP, $\mathrm{DO}, \mathrm{NH}_{3}$, and water temperature were plotted with monitored data of seawater out of the canal outlet. For each factor, values varied according to the water temperature due to the seasonal change. However, those of TN did not show any significant seasonal variation, and the maximum value occurred in November. Values of COD and DO decreased in the summer season when the water temperature is high and increased during the winter season when water temperature is low. Conversely, those of $\mathrm{TP}$ and $\mathrm{NH}_{3}$ were simulated to be the highest in the summer season. Standard deviations of each factor were not significantly larger than $20 \%$ of averaged values $\left(\mathrm{COD}=9.9 \%, \mathrm{TN}=5.7 \%, \mathrm{NH}_{3}=15.5 \%\right.$, $\mathrm{TP}=19.8 \%$, $\mathrm{DO}=2.9 \%$ ). Therefore, we estimated the WQI values with spatially averaged values of all the water quality factors and analyzed the seasonal variation. And we used the values of Chl-a and Secchi Disk depth from the Songdo Sewage Treatment Plant. We selected two alternative scenarios by changing TP or DO concentration of incoming water, dominant factor to evaluate water 
quality. Scenario \#1 was a simulated result with a condition, which an initial condition of TP concentration was $20 \%$ less than current status. Scenario \#2 was a simulated result with DO concentration was $20 \%$ more than the current status. Both scenarios are purified water input from inlets to evaluate which purification method is more effective to increase the water quality in the canal. Hourly-simulated results of two scenarios were plotted with those of current status in Table S1 and Fig. S4. The results of the WQI estimates showed that the overall increase in DO concentration over a year was significantly less than the decrease in TP concentration. In particular, the WQI score from May to August showed that scenario \#2 (+ 20\% of DO concentration case) decreased significantly, that is, water quality would be improved with increased DO concentration. From the hourly estimated data of two scenarios' WQI values were re-estimated as the daily data and the effect of water quality improvement of two scenarios can be confirmed more clearly as shown in Fig. S5. The improvement of water quality with two scenarios also can be analyzed quantitatively with reduction ratio as follows:

$$
R_{m}=\frac{{\sqrt{\left(W_{s, m}-W_{c, m}\right)}}^{2}}{W_{c, m}} \times 100(\%)
$$

where, $R_{m}$ is reduction ratio (\%) of the WQI score. $W_{s}$ and $W_{c}$ are the WQI scores of scenarios and current status, respectively. Subscript $m$ denotes each month (from January to December).

Reduction ratio of alternative scenarios and current status were plotted in Fig. S6. As mentioned previously, effectiveness of DO increase was significantly larger than that of TP decrease from February to September. While the effectiveness of TP reduction was somehow higher from September to October, but $R_{m}$ in this period was only about $10 \%$. Fig. S7 represents the analysis on the WQI scores for two scenarios over a year. Surely, both scenarios do not result in worse consequences, but as mentioned above, the DO scenario showed much more improvement of water quality than the TP scenario. DO scenarios reduced the WQI score to a maximum of 20 points and averagely reduced 7.5 points over a year. On the other hand, the TP scenario reduced the maximum of 4 points only, and the annual average was only about 1.3. Therefore, it was analyzed that the appropriate establishment of the DO concentration control can have a remarkable improvement of the water quality temporally and spatially. Also with analysis, we can expect the improvement of water quality in the canal with operation of submerged aeration facility in the future.

\section{Conclusions and Discussion}

The artificial canal near the west coast in South Korea has been considered water quality topics. Due to the seawater supply into this canal, ecological issues have been discussed in the precious studies so far. Therefore, we tried to understand flow characteristics and pollutant transport in the canal with considering geometrical characteristics and water quality issues. From the numerical analysis, we found the various flow patterns near the con- fluence of the canal and also selected the critical sampling points for the field measurement. And we confirmed the variations of the each water quality issue in the canal after applying ECO-lab module coupled with MIKE 3 FM, flow module. Analyzing the monitored data provided from Korean governmental website, it was revealed that concentration of DO was the highest in September and gradually decreased. And concentrations of TN and TP had large spatial variation along the canal. To determine alternatives of the improvement of water quality in the canal, we simulated DO increase and TP reduction scenarios. The results were compared to the current status in 2013, when the water quality was the worst for the recent five year. The studied canal, constructed only for amenity, is suffering from degradation of water quality. Indeed, water quality can be considered and classified by many aspects and/or purposes. In this study, WQI was considered to evaluate water quality in an artificial channel quantitatively. For the accurate comparison, we applied the WQI with various factors and estimated the WQI for the two scenarios. From the results of the WQI, we found that increasing DO concentration is much more effective than TP concentration control in seawater canal. In general, it is easier to increase DO concentration, by aeration, than reduce $\mathrm{TP}$ concentration in an artificial canal. Therefore, water quality improvement in the canal is expected by suitable operation of aeration facility in the future.

\section{Acknowledgments}

This work was supported by Incheon National University (International Cooperative) Research Grant in 2016.

\section{References}

1. MEIS-KMEMC Korea. Marine Environment Information provided by Korea Marine Environment Management Corporation [internet] Available from: http://www.meis.go.kr.

2. Yeo HG, Kang H. Water quality and phytoplankton community in the coastal waters of Inchon. J. Korean Environ. Sci. Soc. 1998;7:321-326 (in Korean).

3. Carpenter E, Montoya JP, Burns J, Mulholland M, Subramaniam A, Capone DG. Extensive bloom of a N2-fixing diatom/cyanobacterial association in the tropical Atlantic Ocean. Mar. Ecol. Prog. Ser. 1999;185:273-283.

4. Jones AB, Carruthers TJ, Pantus F, Thomas JE, Saxby TA, Dennison WC. A water quality assessment of the Maryland Coastal Bays including nitrogen source identification using stable isotopes. Data report, Univ. of Maryland Center for Environmental Science; 2004.

5. Lee SO, Kim S, Kim M, Lim KJ, Jung Y. The effect of hydraulic characteristics on algal bloom in an artificial seawater canal: A case study in Songdo City, South Korea. Water 2014;6:399-413.

6. Symonds AM, Vijverberg T, Post S, Van der Spek BJ, Henrotte J, Sokolewicz M. Comparison between MIKE 21 FM, Delft3D and Delft3D FM flow models of Western Port Bay, Australia. 
Proceedings of International Conference on Coastal Engineering; 2016; Antalya.

7. Toombes L, Chanson H. Numerical limitations of hydraulic models. Proceedings of the 34th International Association for Hydraulic Research World Congress; 2011; Brisbane. p. 2322-2329.

8. Flow Science. Flow-3D user's manual. Flow Science: Los Alamos, NM, USA; 2003.

9. DHI. MIKE 21 and MIKE 3 Flow Model FM Hydrodynamic and Transport Module-Scientific Documentation. 2017.
10. DHI. MIKE ECO Lab Scientific Description. 2017.

11. Biron P, Best JL, Roy AG. Effects of bed discordance on flow dynamics at open channel confluences. J. Hydraul. Eng. 1996;122:676-682.

12. Lurton Electronic Enterprise Co., Ltd. [Internet]. Available from: http://www.lutron.com.tw.

13. Jang DW, Park HS. Water quality impact assessment of future Songdo Sewage Treatment Plant using Korean water quality index. Int. J. Softw. Eng. Applic. 2015;9:29-40. 